\title{
PERBEDAAN PENGARUH LATIHAN LADDER DRILL DAN SHUTLE RUN TERHADAP KECEPATAN PEMAIN UNGGUL FC MALANG
}

\author{
Krisna Adji Eko Santoso, Anita Faradilla Rahim*, Ali Multazam, Safun Rahmanto, \\ Departement Fisioterapi, Universitas Muhammadiyah Malang, Jalan Bandung No. 1Malang 65133 \\ *Corresponding author: anitafaradilla@umm.acid
}

\begin{abstract}
ABSTRAK
Kecepatan merupakan salah satu kondisi fisik yang cukup berperan dalam permainan futsal seperti saat melewati lawan dan saat melakukan atau terkena serangan balik yang secara tidak langsung mempengaruhi prestasi dari pemain maupun tim futsal sendiri. Latihan yang dapat digunakan untuk meningkatkan kecepatan pada pemain futsal adalah latihan Ladder Drill dan Shuttle Run. Penelitian ini bertujuan untuk mengetahui perbedaan pengaruh pemberian latihan Ladder Drill dan Shuttle Run terhadap peningkatan kecepatan pemain Unggul FC Malang. Desain penelitian ini menggunakan pre-eksperimental dengan two group pretest and post test design untuk pengetahui perbandingan latihan Ladder Dril ldan Shuttle Run terhadap peningkatan kecepatan pemain futsal. Populasi penelitian adalah pemain aktif Unggul FC, responden adalah pemain futsal Unggul FC yang masuk dalam kriteria inklusi dan eksklusi sejumlah 30 orang. Instrument penelitian yang digunakan adalah Sprint 30 Meter Test. Hasil Uji normalitas menunjukkan data tidak normal. Hasil uji Willxocon memiliki hasil yang sama yaitu 0,01<0,05, Hasil uji Mann-Whitney Test 0,001 <0,05. Terdapat perbedaan pengaruh latihan Shuttle Run dan Ladder Drill terhadap peningkatan kecepatan pemain futsal Unggul FC Malang.
\end{abstract}

Keywords: Kecepatan, Ladder Drill, Shuttle Run

\section{PENDAHULUAN}

Salah satu olahraga yang sedang naik daun di masyarakat saat ini adalah futsal. Futsal mampu menyihir masyarakat untuk menggandrungi olahraga ini berkat suasana menyenangkan saat memainkannya. Dalam bermain futsal, dibutuhkan beberapa komponen kemampuan fisik yang memadai seperti kekuatan, akselerasi, kecepatan, keseimbangan dan ketahanan tubuh. Semakin baik kondisi fisik seorang pemain akan berpengaruh terhadap penerapan teknik dan taktik baik itu secara individu maupun tim, komponen fisik diatas tentunya harus dilatih dengan baik tanpa meninggalkan komponen fisik yang lain (Lhaksana, 2012).

Kecepatan adalah sebuah kemampuan dimana tubuh dituntut untuk berpindah serta bergerak dari satu titik ke titik lain dalam waktu sesingkat mungkin (Kusuma, 2017). Kecepatan sendiri merupakan gabungan dari 3 komponen antara lain waktu reaksi, frekuensi gerakan per unit waktu, kecepatan menempuh jarak tertentu. Kecepatan merupakan salah satu kondisi fisik yang cukup berperan dalam permainan futsal seperti saat melewati lawan dan saat melakukan atau terkena serangan balik. Masih banyak pemain futsal saat ini masih belum memiliki kecepatan yang memadai sehingga cukup 
berpengaruh pada permainannya seperti saat melewati lawan dan saat serangan balik dimana kondisi ini secara tidak langsung mempengaruhi prestasi dari pemain maupun tim futsal sendiri (Kusuma, 2017)

Metode latihan untuk meningkatkan kecepatan adalah ladder drill merupakan metode yang cukup sesuai dengan karakteristik permainan futsal dimana pemain dituntut memiliki kecepatan dan kelincahan yang mempuni serta pola latihan ladder drill sendiri baik untuk meningkatkan kecepatan, koordinasi, power serta kelincahan (Tsivkin, 2011).

Selain ladder drills ada juga latihan yang dapat diberikan untuk meningkatkan kecepatan adalah shuttle run adapun cara latihan dengan lari bolak balik secepatnya dari satu titik ke titik lainnya. Unsur gerak pada latihan ini mempunyai komponen yang berpengaruh terhadap peningkatan kecepatan seperti lari sprint dan diikuti dengan gerakan memutar (Zakiuddin, 2019).

\section{METODE}

Metode pada penelitian yang peneliti gunakan ialah metode quasi eksperimental pretest and post-test two group design yang meneliti hubungan sebab-akibat antar dua variabel dependent dan variabel independent dalam waktu yang telah di tentukan. Jumlah Populasi dalm penelitian ini sebanyak 53 orang dan yang masuk sampel sebanyak 30 orang. Pengukuran kelincahan menggunakan Sprint 30 Meter Test. Uji normalitas pada penelitian ini mempergunakan uji Shapiro Wilk,uji pengaruh yang digunakan adalah wilcoxon singed rank test untuk menguji hipotesis dimana datanya berpasangan dan hasil uji normalitasnya mendapatkan nilai tidak normal dan Uji beda pengaruh yang digunakan adalah uji mann whitney.

\section{HASIL PENELITIAN}

1. Karakteristik Responden berdasrkan IMT Berikut ini merupakan tabel karakteristik responden berdasarkan indek masa tubuh (IMT)
Tabel 1 IMT Responden

\begin{tabular}{ccc}
\hline IMT & Persentase & Jumlah \\
\hline Normal & 68 & 20 \\
\hline Pre Obes & 32 & 10 \\
\hline
\end{tabular}

Berdasarkan tabel diatas terdapat beberapa kategori penggolongan indeks masa tubuh. Menurut WHO asian-BMI classification yang di publikasikan tahun 2009 terdapat beberapa kategori pembagian kategori IMT didalam penelitian ini sebanyak 20 orang pada kategori normal (68\%) dan 10 orang pada kategori pre obesity $(32 \%)$.

2. Identifikasi Responden Berdasarkan Nilai Kecepatan Sebelum dan Sesudah Diberikan Intervensi Ladder Drill dan Shuttle Run.

Berikut ini merupakan nilai rata rata kecepatan responden sebelum dan sesudah diberi intervensi.

Tabel 2 Rata - Rata Nilai Kecepatan

\begin{tabular}{cccc}
\hline Latihan & Pre & Post & Selisih \\
\hline LadderDrill & 4,85 & 4,64 & 0,21 \\
\hline Shuttle Run & 4,54 & 4,25 & 0,29 \\
\hline
\end{tabular}

Berdasarkan data di atas dapat diidentifikasikan perubahan kecepatan 30 responden sebelum dan sesudah diberikan latihan dengan sebaran kelompok latihan ladder drill dengan nilai pretest 4,85 detik dan posttest 4,64 detik serta selisih 0,21 detik kemudian kelompok latihan shuttle run dengan nilai pretest 4,54 detik dan posttest 4,25 detik serta selisih 0,29 detik.

3. Uji Normalitas

Berikut hasil uji normalitas yang dimana menggunakan uji shapiro-wilk dengan sapel sebanyak 30 orang responden. 
Tabel 3 Uji Normalitas

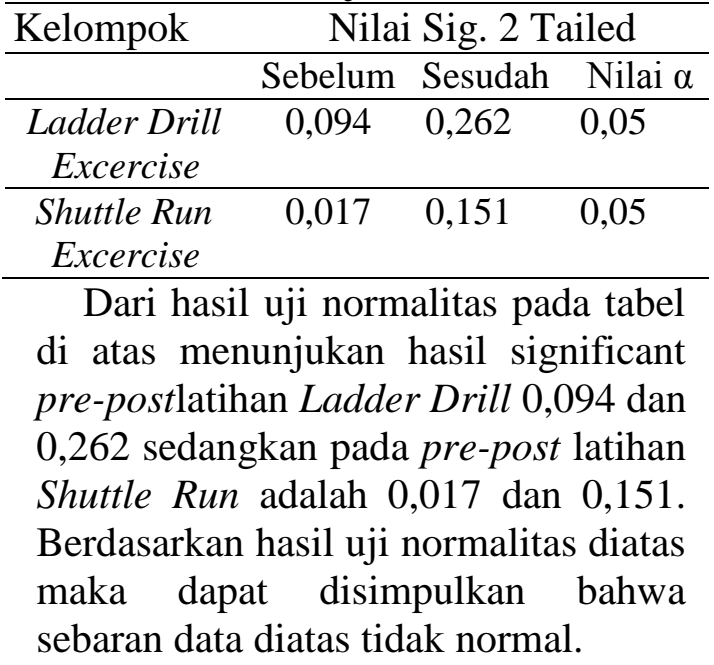

4. Pengaruh Latihan Ladder Drill Terhadap Kecepatan Pemain Unggul FC Malang

Tabel 4 hasil uji wilxocon kelompok

\begin{tabular}{ccc}
\multicolumn{3}{c}{ ladder drill } \\
\hline Kelompok & $\mathrm{n}$ & Sig.2-tailed \\
\hline $\begin{array}{c}\text { Ladder } \\
\text { Dril }\end{array}$ & 15 & 0,001
\end{tabular}

Wilcoxon: $\mathrm{n}=$ Total Frekuensi; Sig.2-tailed= Pengujian dua arah; $\alpha=$ Signifikansi

Hasil uji Wilcoxon kelompok ladder drill diperoleh nilai signifikansi senilai 0,001 atau lebih kecil dari 0,05. Kesimpulan yang dapat ditarik dari data diatas adalah terdapat pengaruh pemberian latihan ladder drill terhadap peningkatan kecepatan pemain Unggul FC Malang.

5. Pengaruh Latihan Shuttle Run Terhadap Kecepatan Pemain Unggul FC Malang

Tabel 5 hasil uji wilxocon kelompok shuttle run

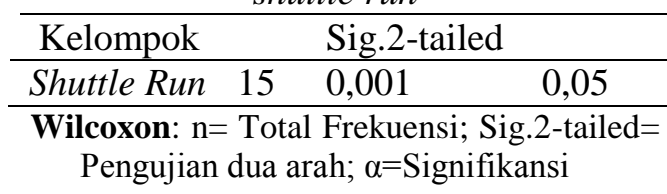

Hasil uji Wilcoxon kelompok shuttle run nilai signifikansinya sebesar
0,001 yang berarti lebih kecil dari nilai asebesar 0,05. Kesimpulan dari hasil tersebut adalah terdapat pengaruh pemberian latihan shuttle run terhadap peningkatan kecepatan pemain Unggul FC Malang.

6. Perbandingan Efektifitas Latihan Ladder Drill dan Shuttle Run Terhadap Peningkatan Kecepatan Pemain Unggul FC Malang

Tabel 6 hasil uji Mann-Whitney

\begin{tabular}{cccc}
\hline & $\mathrm{n}$ & $\begin{array}{l}\text { Sig.2- } \\
\text { tailed }\end{array}$ & $\alpha$ \\
\hline Perbandingan & & & \\
pengaruh & & & \\
Ladder drill & & & \\
Excercise & 30 & 0,006 & 0,05 \\
dan Shuttle & & & \\
$\quad$ Run & & & \\
Excercise & & & \\
\hline
\end{tabular}

Mann-Whitney: $\mathrm{n}=$ Total Frekuensi; Sig.2tailed $=$ Pengujian dua arah; $\alpha=$ Signifikansi

Berdasarkan tabel 6 menunjukan total sampel keseluruhan sebanyak 30 orang dan hasil dari uji perbandingan pengaruh latihan menggunakan uji mann-whitney diperoleh data senilai $0,006<\alpha=0,05$. Berdasarkan tabel diatas dapat disimpulkan bahwasanya H0 ditolak dan H1 diterima dan diartikan berupa terdapat perbedaan pengaruh pemberian latihan Ladder Drill dan Shuttle Run terhadap peningkatan kecepatan pemain Unggul FC Malang.

\section{PEMBAHASAN}

Dalam penelitian ini responden yang memiliki Indeks Massa Tubuh (IMT) terbanyak dengan kategori normal mencapai 20 orang atau $66,7 \%$. Menurut DepKes (2003) IMT merupakan rasio dari berat badan serta tinggi badan yang meliputi ujung rambut sampai dengan ujung kaki.

Berat badan berlebihan akan 
cenderung memiliki gerak yang lebih lamban yang disebabkan oleh badan ekstra serta kurangnya fleksibilitas pada saat melakukan gerakan (Asy'ari, 2018). Sedangkan menurut Bahrudin (2008) berat badan adalah parameter gambaran massa tubuh dan parameter antropometri yang labil sehingga berat badan yang berlebih mengurangi kelincahan serta kecepatan karena adanya friksi pada jaringan lemak serabut otot sehingga berkurangnya kontraksi otot.

Ladder drill merupakan bentuk latihan menggunakan ladder yang diletakan pada permukaan lantai yang sangat baik untuk meningkatkan kecepatan, koordinasi, kelincahan dan power secara keseluruhan(Kusuma, 2017). Latihan ini melatih otot tungkai agar lebih kuat karena pada saat satu kaki melompat kaki sebelahnya menahan berat tubuh walaupun hanya sebentar dan latihan ini berfokus pada gerakan cepat kaki agar kedua kaki menjadi lebih terlatih (Qonitin, 2015).

Pada saat latihan tubuh akan mengalami respon secara fisiologi. Latihan akan berefek akut atau sesaat pada sistem neuromuscular, sistem hormonal, sistem cardivaskular, dan metabolisme (Sebastianus, 2011). Berdasarkan penelitian Chandrakumar dan Ramesh (2015) berjudul Effect Ladder Drills and SAQ Training on Agility and Speed Among Sport Club Badminton Player dimana latihan ladder drill akan meningkatkan reaksi dan sistem neuromuscular yang akan meningkatkan kecepatan dan kelincahan. Peningkatan presentasi dari aktivasi motor unit akan membuat adaptasi neuromuscular. Latihan ladder drill akan meningkatkan kecepatan, kelincahan serta koordinasi serta konduksitivitas saraf sehingga menyebabkan meningkatnya koordinasi pada neuromuscular sehingga akan membentuk efektifitas dan efisiensi dari gerakan tungkai.

Latihan shuttle run atau lari bolakbalik secepat-cepatnya dimulai dari satu titik ke titik lainnya dengan jarak 4-5 meter. Unsur gerakan pada latihan shuttle run yaitu lari dengan mengubah arah dan posisi tubuh sehingga akan meningkatkan kecepatan serta kelincahan. Latihan shuttle run sendiri berorientasi pada kecepatan, kelincahan serta footwork.

Menurut Fitria (2014) ketika seseorang berlari otomatis otot akan mengalami kontraksi baik kontraksi isotonik dan isometrik. Kontraksi isometrik terjadi tanpa adanya sliding dari filament dan sebaliknya kontraksi isotonik menyebabkan pemendekan otot namun masih toleril. Dalam fase berlari akan terjadi kedua kontraksi tersebut dimana kontraksi isotonik berfungsi menggerakkan tungkai kaki dan kontraksi isotonik mempertahankan tungkai. Pada saat pemain mengurangi kecepatan sebelum mengubah arah 180 derajat untuk kembali ke titik awal sehingga memerlukan kontraksi secara bergantian pada otot tertentu sehingga otot perentang seperti knee extensor dan hip ekstensor mengalami kontarksi eksentrik saat memperlambat gerakan tubuh ke depan yang ototmatis memacu tubuh ke arah posisi yang baru.Penerapan prinsip serta metode dasar latihan secara sistematis dan secara berulang dalam jangka waktu yang lama maka secara otomatis akan meningkatkan aktifitas serta kerja mitokondria di dalam sel otot(Santoso, 2016).

Latihan ladder drill akan meningkatkan presentasi akivasi motor unit yang membuat neuromuscular beradaptasi dimana otot-otot akan lebih elastis dan ruang gerak sendi semakin baik sehingga menyebabkan ayunan tungkai saat melakukan gerakan lebih lebar dan besar. Dengan meningkatkan komponen tersebut maka kecepatan akan mengalami peningkatan. Menurut Rahman (2018) otot yang teraktivasi ialah otot ekstermitas bawah seperti M. Soleus, M. Plantaris, M. Tibialis, M. Peroneus, M. Gastrocnemius, 
M. Semitendinosus, M. Biceph Femoris, M. Gluteus Maximus.

Menurut Womsiwor (2014) latihan shuttle run secara berulang akan menyebabkan hipertropy otot yang terjadi dikarenakan bertambahnya jumlah myofibril pada serabut otot. Peningkatan serabut otot terjadi pada serabut otot putih atau fast twitch sehingga terjadi peningkatan kecepatan kontraksi pada otot. Dengan terjadinya peningkatan kecepatan dalam mengkontraksikan otot maka akan menyebabkan peningkatan kecepatan dan kelincahan pada pemain. Menurut Deane (2005) otot yang dominan digunakan adalah M. Plantar Flexor, M. Quadriceph, M. Gluteus Maximus.

Hasil penelitian ini sendiri meyimpulkan bahwa latihan shuttle run lebih baik untuk latihan meningkatkan kecepatan karena pola latihan dari shuttle run menggunakan lari sprint bolak-balik dalam jarak 5 meter maka atlet akan terbiasa melakukan sprint serta hipertropy pada otot dan peningkatan kecepatan kontraksi otot dibanding latihan ladder drill yang berfokus pada footwork serta kelincahan pemain pada komponen latihannya pada saat melewati ladder.

\section{KESIMPULAN}

Berdasarkan hasil penelitian dan pembahasan didapatkan hasil bahwa shuttle run exercise dan ladder drill exercise memiliki pengaruh terhadap peningkatan kecepatan. Terdapat perbedaan pengaruh yang signifikan pada latihan ladder drill dan shuttle run.

\section{DAFTAR PUSTAKA}

Asy'ari, M. A. (2018). Pengaruh Kombinasi Core Stability Exercise dan Sprint Training Terhadap Peningkatan Kelincahan Pada Pemain Futsal Universitas Muhammadiyah Malang (Doctoral dissertation, University of Muhammadiyah Malang).
Bahrudin, yamin., Mayulu, N., \& Rottie, J. (2008). Hubungan Asupan Energi dengan Kejadian Obesitas pada Siswa Sekolah Dasar di Kota Manado. JURNAL KEPERAWATAN, 1(1).

Chandrakumar, N., \& Ramesh, C. (2015). Effect of ladder drill and SAQ training on speed and agility among sports club badminton players. International Journal of Applied Research, 1(12), 527-529.

Deane, R. S., Chow, J. W., Tillman, M. D., \& Fournier, K. A. (2005). Effects of hip flexor training on sprint, shuttle run, and vertical jump performance. The Journal of Strength \& Conditioning Research, 19(3), 615-621.

Depkes, R. I. (2003). Survey Indeks Masa Tubuh (IMT) Pengumpulan Status Gizi Orang Dewasa Berdasarkan IMT. Direktorat Bina Gizi Masyarakat.

Fitria, R. (2014). Aktivitas Otot Rangka Saat Berlari, Yogyakarta: FK UII

Kusuma, K. C. A., \& Kardiawan, I. K. H. (2017). Pengaruh pelatihan ladder drill terhadap kecepatan dan kelincahan.Semin. Nas. Ris. Inov, 5, 16-20.

Lhaksana, Justinus. (2012). Taktik \& Strategi Futsal Modern. Jakarta: Be Champion.

Qonitin Syahida, H. (2015). Pengaruh Latihan Ladder Drill Two Feet Each Square dan Zig-Zag Run Terhadap Tingkat Kecepatan Berlari 50 Meter Pada Pemain Sepak Bola (Doctoral dissertation, Universitas Muhammadiyah Surakarta).

Rahman, F. J. (2018). Peningkatan Daya Tahan, Kelincahan, dan Kecepatan 
pada Pemain Futsal: Studi Eksperimen Metode Circuit Training. Jurnal SPORTIF: Jurnal Penelitian Pembelajaran, 4(2), 264-279.

Santoso, D. R., \& Kurniawati, D. (2016). Pengaruh Latihan Shuttle Run Dan Nebraska Agility Drill Terhadap Kelincahan Pada Pemain Sepakbola Di Pusat Latihan Sepakbola Salatiga (Doctoral dissertation, Universitas Muhammadiyah Surakarta).

Sebastianus Pranatahadi. (2011). Fisiologi Latihan. Yogyakarta: FIK UNY.
Tsivkin, Troman. (2011). http: $/ / w w w . s p o r t-f i t n e s s-a d v i s o r . c o m . \mathrm{di}$ unduh tanggal 10 September 2019

Womsiwor, Daniel dan I Nengah Sandi. (2014). Pelatihan Lari Sircuit Haluan Kiri Lebih Baik Dari Pada Haluan Kanan Untuk Meningkatkan Kelincahan Pemain Sepakbola Siswa SMK X Denpasar. Sport and Fitnes Journal,2(1), 1017,Maret 2014

Zakiuddin, A. R. (2019). Pengaruh Latihan Shuttle Run dan Corner Drill Terhadap Kelincahan Pada Siswa SMP Muhammadiyah 1 Gisting Tahun Pelajaran 2018/2019. Universitas Lampung. 